\title{
PŁYTY ŚREDNIEJ GRUBOŚCI HENCKY'EGO-BOLLE'A NA PODŁOŻU SPRĘŻYSTYM
}

\author{
Mykola Nagirniak ${ }^{凶}$ \\ Instytut Inżynierii Lądowej, Szkoła Główna Gospodarstwa Wiejskiego w Warszawie
}

\begin{abstract}
STRESZCZENIE
W pracy przedstawiono równania teorii płyt spoczywających na jednokierunkowych podłożach sprężystych. Rozpatrzono teorie płyt cienkich i średniej grubości spoczywających na podłożach jedno- i dwuparametrowych, w tym na podłożu Winklera oraz Własowa. Rozpatrzono przypadek przyłożenia obciążenia ,samorównoważnego" do brzegu półpasma spoczywającego na podłożu sprężystym Winklera i Własowa. Wykazano, że tzw. efekt brzegowy występuje wyłącznie w płytach średniej grubości bez podłoża i płytach spoczywających na podłożu jednoparametrowym Winklera oraz dwuparametrowym Własowa. Przeanalizowano wpływ współczynnika Poissona materiału płyty na wartości ugięć oraz sił przekrojowych w półpaśmie płytowym spoczywającym na podłożu gruntowym, na który działa obciążenie „samorównoważne”. Porównano rozwiązanie według teorii płyt Hencky'ego-Bolle’a półpasma płytowego spoczywającego na podłożu Winklera oraz Własowa.
\end{abstract}

Słowa kluczowe: płyty Kirchhoffa, płyty Hencky’ego-Bolle’a, efekt brzegowy, podłoże Własowa, podłoże Winklera, obciążenie „samorównoważne”

\section{WSTĘP}

Teoria belek i płyt na podłożu sprężystym jest bardzo obszernym rozdziałem współczesnej mechaniki budowli. W tej dziedzinie wykonano olbrzymią liczbę badań. Istniejące metody obliczeń nie są jednak idealne. Same hipotezy opisujące przemieszczenia w podłożu gruntowym również nie są w pełni satysfakcjonujące. W wielu przypadkach otrzymane wyniki różnią się znacznie od rzeczywistych. Metody obliczeń półprzestrzeni sprężystej są bardzo skomplikowane istosowane w ograniczonym zakresie (Vlasov i Leontiev, 1960). Pojawiają się trudności z automatyzacją obliczeń zarówno na etapie obliczeń symbolicznych, jak i całkowania numerycznego (Jemioło i Szwed, 2017).

W teorii płyt cienkich pominięto wpływ sił poprzecznych na ugięcia. W przypadku płyt średniej gru- bości wpływ ten jest znaczny i należy go uwzględnić w obliczeniach (Jemielita, 2001). W niniejszej pracy (w odróżnieniu od monografii Własowa i Leontiewa) rozpatrzono uogólnioną teorię płyt średniej grubości Hencky'ego-Bolle'a na podłożu sprężystym Winklera i Własowa, którego własności opisywane są dwoma uogólnionymi charakterystykami. Przy działaniu obciążenia „samorównoważnego" na brzeg swobodny półpasma bez uwzględnienia podłoża gruntowego według teorii płyt Kirchhoffa uzyskuje się rozwiązanie zerowe, a według teorii Hencky'ego-Bolle'a niezerowe (Nagirniak, 2019).

\section{RÓWNANIA RÓŻNICZKOWE PŁYT KIRCHHOFFA I HENCKY'EGO-BOLLE'A}

Znane równanie teorii izotropowych płyt cienkich zapisujemy w postaci: 


$$
D \nabla^{4} w=p_{3}
$$

zaś równania uogólnionej teorii Hencky'ego-Bolle'a następująco (Jemielita, 2001):

$$
\begin{aligned}
& D \nabla^{4} w=p_{3}-\frac{D}{K} \nabla^{2} p_{3} \\
& \nabla^{2} \psi-\frac{2 K}{D(1-v)} \psi=0
\end{aligned}
$$

gdzie:

$\psi=\epsilon^{\alpha \beta} \phi_{\alpha, \beta}-$ część rotacyjna wektora przemieszczenia, $\epsilon^{\alpha \beta}$ - symbol permutacyjny Ricciego,

$\phi_{\alpha}$ - kąty obrotu wyznaczane ze wzoru

$\phi_{\alpha}=w_{, \alpha}+\frac{D(1-v)}{2 K}\left[\epsilon^{\alpha \beta} \psi_{, \beta}+\frac{2}{1-v} \nabla^{2} w_{, \alpha}+\frac{2 p_{3, \alpha}}{(1-v) K}\right]$

w którym:

$w$ - funkcja ugięcia płyty,

$p_{3}$ - obciążenie prostopadłe do płaszczyzny środkowej płyty,

$D=\frac{E h^{3}}{12\left(1-v^{2}\right)}-$ sztywność płyty na zginanie,

$K=\kappa h G-$ sztywność na ścinanie płyty,

$\kappa=\frac{5}{6}-$ współczynnik ścinania (Jemielita, 2002),

$h$ - grubość płyty,

$E$ - moduł Younga,

$G-$ moduł Kirchhoffa,

$\alpha, \beta=1,2$,

$v$ - współczynnik Poissona materiału płyty.

Naturalne warunki brzegowe są następujące:

- w teorii płyt Kirchhoffa $M_{n}=\hat{M}_{n}, V_{n}=\hat{V}_{n}$, przy czym $V_{n}$ jest zastępczą siłą Kirchhoffa, określoną wzorem $V_{n}=Q_{n}+\frac{\partial M_{n s}}{\partial s}$,

- w teorii płyt Hencky'ego-Bolle'a są trzy naturalne warunki brzegowe: $M_{n}=\hat{M}_{n}, M_{n s}=\hat{M}_{s}, Q_{n}=\hat{Q}_{n}$, gdzie wielkości z „daszkiem” są wartościami obciążeń na brzegu płyty.

\section{MODELE JEDNOKIERUNKOWE, JEDNO- I DWUPARAMETROWE PODŁOŻY SPRĘŻYSTYCH}

Dwuwymiarowe modele podłoża sprężystego dzielimy na dwie grupy:

- modele powstałe z równań teorii sprężystości po wprowadzeniu pewnych uproszczeń (więzów), zwane modelami strukturalnymi,

- modele powstałe z kombinacji (układu) warstw o różnych charakterystykach materiałowych; są to tzw. wieloparametrowe modele fenomenologiczne (Jemielita, 1992, 1994).

Rozpatrzymy oba typy modeli, oznaczając przez $q\left(x_{\alpha}\right)$ obciążenie działające na podłoże, a przez $w_{g}\left(x_{a}, z\right)$ przemieszczenie wzdłuż osi Z (rys. 1). Równanie jednokierunkowego, jednoparametrowego podłoża Winklera zapiszemy w postaci:

$$
q\left(x_{\alpha}\right)=k_{1} w_{g}\left(x_{\alpha}\right)
$$

gdzie $k_{1}$ jest sztywnością podłoża liczoną $\mathrm{w} \mathrm{N} \cdot \mathrm{m}^{-3}$.

Jest to model fenomenologiczny złożony z układu niezależnych sprężyn.

Innym modelem fenomenologicznym jest model dwuparametrowy, którego równanie zapiszemy w postaci

$$
q\left(x_{\alpha}\right)=k_{1} w_{g}\left(x_{\alpha}\right)-k_{2} \nabla^{2} w_{g}\left(x_{\alpha}\right)
$$

gdzie $k_{2}$ jest sztywnością liczoną $\mathrm{w} \mathrm{N} \cdot \mathrm{m}^{-1}$.

Jest to model podłoża złożonego $\mathrm{z}$ dwóch warstw: warstwy sprężyn i warstwy czułej na ścinanie - model Pasternaka (1954), lub z naprężonej błony na układzie sprężyn - model Fiolonenko-Borodicha (1940).

W modelu Pasternaka sztywność $k_{2}$ możemy wyznaczyć ze wzoru $k_{2}=G_{g} h_{g}$, a w modelu Fiolonenko-Borodicha $k_{2}=N$, gdzie: $h_{g}$ jest grubością warstwy gruntu czułej na ścinanie, $G_{g}$ modułem Kirchhoffa gruntu, a $N$ siłą napinającą błonę.

Modelem strukturalnym jest model Własowa (Vlasov i Leontiev, 1960). Jest to model jednowarstwowy o dwóch parametrach. Jego równanie, przy przyjęciu $u_{\alpha}\left(x_{\alpha}, z\right)=0, u_{3}\left(x_{\alpha}, z\right)=w_{g}\left(x_{\alpha}\right) \vartheta(z)$, ma postać (6), w której (Vlasov i Leontiev, 1960, s. 138 - wzór 1.4): 


$$
\begin{aligned}
& k_{1}=k=\frac{E_{g}\left(1-v_{g}\right)}{\left(1+v_{g}\right)\left(1-2 v_{g}\right)} \int_{0}^{h_{g}}\left(\frac{d}{d z}(\vartheta(z))\right)^{2} d z \\
& k_{2}=2 t=\frac{E_{g}}{2\left(1+v_{g}\right)} \int_{0}^{h_{g}} \vartheta(z)^{2} d z
\end{aligned}
$$

Funkcja $\vartheta(z)$ jest funkcją zanikania przemieszczeń w podłożu, przy czym przyjmujemy $\vartheta(0)=1$. Równanie modelu podłoża Własowa zapiszemy w postaci

$$
q\left(x_{\alpha}\right)=k w_{g}\left(x_{\alpha}\right)-2 t \nabla^{2} w_{g}\left(x_{\alpha}\right)
$$

Własow proponuje przyjąć następujące postacie funkcji $\vartheta(z)$ :

- funkcję liniową

$$
\vartheta(z)=1-\frac{z}{h_{g}}
$$

- funkcję hiperboliczną

$$
\vartheta(z)=\frac{\operatorname{sh}\left[\gamma\left(h_{g}-z\right)\right]}{\operatorname{sh}\left[\gamma h_{g}\right]}=\frac{\operatorname{sh}\left[\gamma_{1}\left(1-\frac{z}{h_{g}}\right)\right]}{\operatorname{sh}\left[\gamma_{1}\right]}
$$

gdzie:

$\gamma$ - współczynnik zanikania osiadań gruntu liczonym $\mathrm{w} \mathrm{N} \cdot \mathrm{m}^{-1}$,

$\gamma_{1}$ - bezwymiarowy współczynnik.

\section{RÓWNANIE RÓŻNICZKOWE PŁYT NA PODŁOŻU SPRĘŻYSTYM}

Przyjmujemy, że kontakt między płytą a podłożem zawsze istnieje. Oznacza to spełnienie równości $w\left(x_{\alpha}\right)=w_{g}\left(x_{\alpha}, 0\right)$. Przy tym założeniu zawsze zachodzi interakcja między płytą a podłożem. Na płytę działa obciążenie odniesione do płaszczyzny środkowej płyty, równe

$$
p_{3}\left(x_{\alpha}\right)=p\left(x_{\alpha}\right)-q\left(x_{\alpha}\right)
$$

gdzie $p$ jest obciążeniem zewnętrznym.

Wstawiając (10) do równań (1) i (2) i uwzględniając (5), (6) i (8), otrzymujemy następujące równania różniczkowe:
- płyty cienkiej na podłożu Winklera

$$
D \nabla^{4} w\left(x_{\alpha}\right)+k_{1} w\left(x_{\alpha}\right)=p\left(x_{\alpha}\right)
$$

- płyty cienkiej na podłożu Własowa

$\nabla^{4} w\left(x_{\alpha}\right)-2 r^{2} \nabla^{2} w\left(x_{\alpha}\right)+s^{4} w_{g}\left(x_{\alpha}\right)=\frac{p\left(x_{\alpha}\right)}{D}$

gdzie: $r^{2}=\frac{t}{D}, s^{4}=\frac{k}{D}$

- płyty średniej grubości na podłożu Winklera

$$
\begin{aligned}
& \nabla^{4} w\left(x_{\alpha}\right)-2 r_{1}^{2} \nabla^{2} w\left(x_{\alpha}\right)+s_{1}{ }^{4} w\left(x_{\alpha}\right)= \\
& =\frac{p\left(x_{\alpha}\right)}{D}-\frac{1}{K} \nabla^{2} p\left(x_{\alpha}\right)
\end{aligned}
$$

gdzie:

$$
r_{1}^{2}=\frac{k_{1}}{2 K}, \quad s_{1}^{4}=\frac{k_{1}}{D}
$$

- płyty średniej grubości na podłożu dwuparametrowym

$$
\begin{aligned}
& \nabla^{4} w\left(x_{\alpha}\right)-2 r_{2}^{2} \nabla^{2} w\left(x_{\alpha}\right)+s_{2}^{4} w\left(x_{\alpha}\right)= \\
& =\frac{p\left(x_{\alpha}\right)}{D}-\frac{1}{K} \nabla^{2} p\left(x_{\alpha}\right)
\end{aligned}
$$

gdzie:

$$
r_{2}^{2}=\frac{\left(\frac{k_{1}}{K}+\frac{k_{2}}{D}\right)}{2\left(1+\frac{k_{2}}{K}\right)}, s_{2}^{4}=\frac{k_{1}}{D\left(1+\frac{k_{2}}{K}\right)}
$$

- płyty średniej grubości na podłożu Własowa

$$
\begin{aligned}
& \nabla^{4} w\left(x_{\alpha}\right)-2 r_{3}^{2} \nabla^{2} w\left(x_{\alpha}\right)+s_{3}^{4} w\left(x_{\alpha}\right)= \\
& =\frac{p\left(x_{\alpha}\right)}{D}-\frac{1}{K} \nabla^{2} p\left(x_{\alpha}\right)
\end{aligned}
$$

gdzie:

$$
r_{3}^{2}=\frac{\left(\frac{k}{K}+\frac{t}{D}\right)}{2\left(1+\frac{t}{K}\right)}, s_{3}^{4}=\frac{k}{D\left(1+\frac{t}{K}\right)}
$$

Zauważmy, że równania płyty średniej grubości na podłożu czy to Winklera, czy Własowa mają taką samą postać i różnią się tylko współczynnikami. 


\section{ROZWIĄZANIE WEDŁUG TEORII PŁYT KIRCHHOFFA PÓŁPASMA PŁYTOWEGO SPOCZYWAJĄCEGO NA PODŁOŻU SPRĘŻYSTYM}

Rozpatrzmy półpasmo płytowe przegubowo podparte spoczywające na podłożu sprężystym, na którego brzeg swobodny działa obciążenie „samorównoważne", jak pokazano na rysunku 1 .

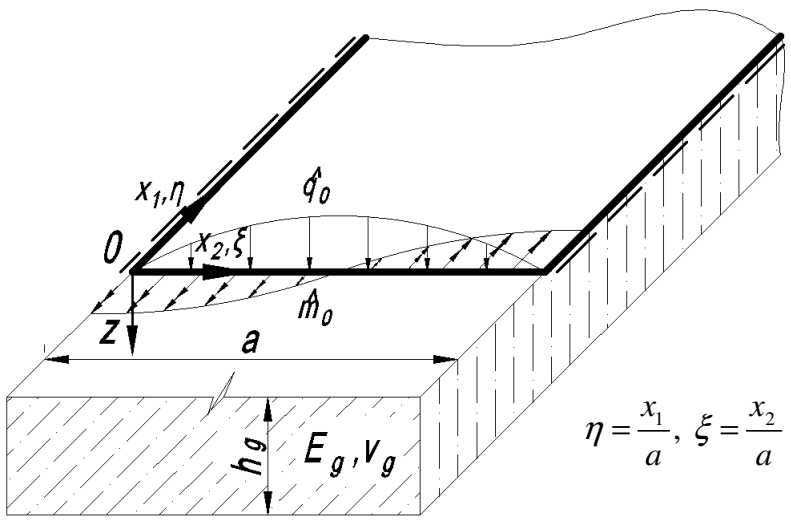

Rys. 1. Półpasmo płytowe na podłożu sprężystym

Fig. 1. Plate half-band on an elastic subsoil

Warunki brzegowe zapiszemy w postaci:

$M_{11}(0, \xi)=0, V(0, \xi)=-\hat{q}_{0}(\xi)-\frac{1}{a} \frac{\partial \hat{m}_{0}(\xi)}{\partial \xi}=0$.

Jak wykazano w pracy Nagirniaka (2019), obciążenie „samorównoważne” nie wywołuje przemieszczeń, a przy tym i sił przekrojowych w przypadku rozwiązania według teorii Kirchhoffa bez uwzględnienia podłoża gruntowego. W przypadku płyty cienkiej spoczywającej na podłożu zarówno Winklera, jak i Własowa także nie ma oddziaływań od takiego obciążenia. Możemy powiedzieć, że płyta cienka spoczywająca na podłożu czy to Winklera, czy Własowa „nie widzi” tego typu obciążenia „samorównoważnego” brzegu swobodnego płyty.

\section{ROZWIAZZANIE WEDŁUG TEORII PŁYT HENCKY'EGO-BOLLE'A PÓŁPASMA PŁYTOWEGO SPOCZYWAJĄCEGO NA PODŁOŻU SPRĘŻYSTYM WINKLERA}

Rozpatrzmy półpasmo płytowe przegubowo podparte na brzegach (przy $\xi=0 \mathrm{i} \xi=1$ ), na którego brzeg swobodny (przy $\eta=0$ ) działa obciążenie „samorówno- ważne" siłą poprzeczną $\hat{q}_{0}(\xi)=Q \sin (\pi \xi)$ i momentem skręcającym $m_{0}(\xi)=\frac{Q a}{\pi} \cos (\pi \xi)$, jak pokazano na rysunku 1. Równanie (11) przyjmie postać

$$
\nabla^{4} w\left(x_{\alpha}\right)-2 r_{1}^{2} \nabla^{2} w\left(x_{\alpha}\right)+s_{1}{ }^{4} w\left(x_{\alpha}\right)=0
$$

gdzie $r_{1}^{2}$ i $s_{1}^{4}$ są określone wzorem (12).

Rozwiązanie jednorodnego układu równań (15) i (3) przewidujemy w postaci:

$$
\begin{gathered}
w(\eta, \xi)=\left(e^{-\theta_{1} \eta} C_{1}+e^{-\theta_{2} \eta} C_{2}\right) \sin (\pi \xi) \\
\psi(\eta, \xi)=\frac{e^{-\theta_{3} \eta} C_{3}}{a} \cos (\pi \xi)
\end{gathered}
$$

gdzie:

$$
\theta_{1}=\sqrt{\pi^{2}+a^{2} r_{1}^{2}-\sqrt{a^{4}\left(r_{1}^{4}-s_{1}^{4}\right)}}
$$

$\theta_{2}=\sqrt{\pi^{2}+a^{2} r_{1}^{2}+\sqrt{a^{4}\left(r_{1}^{4}-s_{1}^{4}\right)}}$

$\theta_{3}=\pi \sqrt{1+\frac{10}{\pi^{2} \delta^{2}}}$

$\delta=\frac{h_{p}}{a}-$ stosunek grubości płyty $h_{p}$ do jej szerokości $a$.

Momenty zginające, skręcające i siły poprzeczne wyznaczymy ze wzorów (Jemielita, 2001):

$$
\begin{gathered}
M_{\alpha \beta}=D\left[(1-v) \kappa_{\alpha \beta}+v \kappa_{\gamma}^{\gamma} \delta_{\alpha \beta}\right]+\frac{v h^{2} p_{3}}{10(1-v)} \delta_{\alpha \beta} \\
Q_{\alpha}=K \chi_{\alpha} \\
\kappa_{\alpha \beta}=-\frac{1}{2}\left(\phi_{\alpha, \beta}+\phi_{\beta, \alpha}\right) \\
\chi_{\alpha}=w_{, \alpha}-\phi_{\alpha}
\end{gathered}
$$

gdzie:

$\delta_{\alpha \beta}-$ delta Kroneckera,

$\phi_{\alpha}$ - kąty obrotu podane wzorem (4).

Warunki brzegowe zapiszemy w postaci: $M_{11}(0, \xi)=0, M_{12}(0, \xi)=-\hat{m}_{0}, Q_{1}(0, \xi)=-\hat{q}_{0}$.

Przyjmując liniową funkcje zanikania przemieszczeń $\vartheta(z)$ w postaci (9) i współczynnik sprężystości 
podłoża $k_{1}$ według Własowa (Vlasov i Leontiev, 1960) $\mathrm{W}$ postaci $k_{1}=\frac{G_{g}\left(1-v_{g}\right)}{h_{g}\left(1-2 v_{g}\right)}$, po uwzględnieniu warunków brzegowych znajdziemy niewiadomą funkcję przemieszczeń $w(\eta, \xi)$. Zakładając

$\delta=\frac{h}{a}=\frac{1}{10}, \delta_{1}=\frac{h_{g}}{a}=1, \delta_{2}=\frac{v_{g}}{v_{p}}=1, \delta_{3}=\frac{G_{g}}{G_{p}}=\frac{1}{500}$ gdzie:

$\delta_{1}-$ stosunek grubości warstwy gruntu do szerokości płyty,

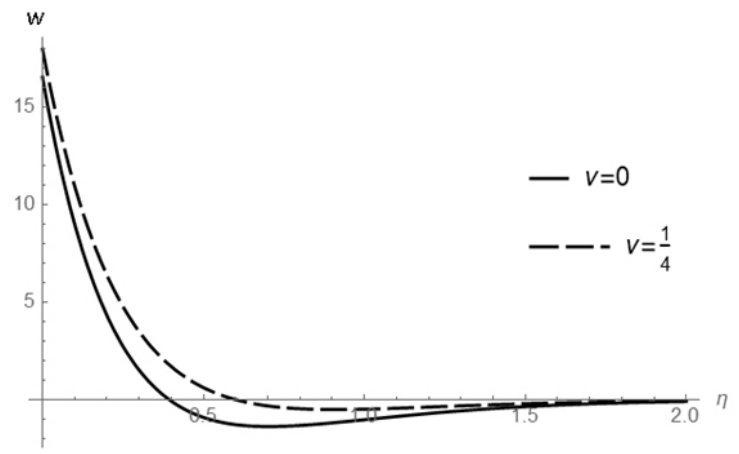

Rys. 2. Wykres ugięcia $\frac{w G_{p}}{Q}$ półpasma na podłożu Winklera dla $\xi=1 / 2$

Fig. 2. Graph of deflection $\frac{w G_{p}}{Q}$ of plate on the Winkler subsoil for $\xi=1 / 2$

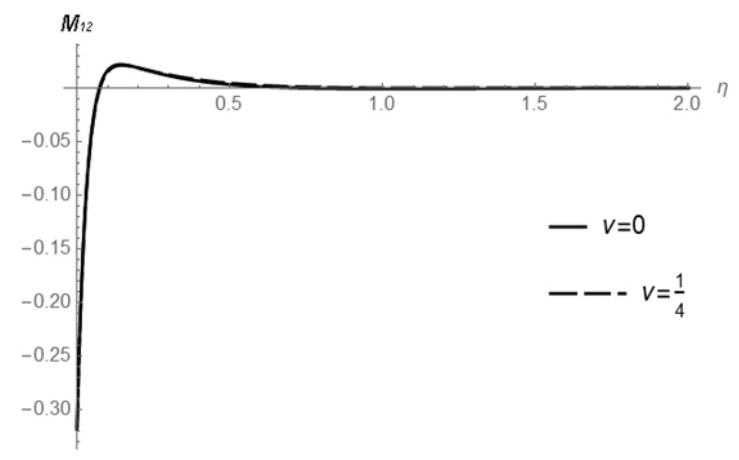

Rys. 4. Wykres momentów skręcających $\frac{M_{12}}{a Q}$ w półpaśmie na podłożu Winklera dla $\xi=0$

Fig. 4. Graph of the torsional moments $\frac{M_{12}}{a Q}$ in the plate on the Winkler subsoil for $\xi=0$ $\delta_{2}$ - stosunek współczynnika Poissona gruntu do współczynnika Poissona płyty,

$\delta_{3}-$ stosunek modułu sprężystości gruntu do modułu sprężystości płyty,

na rysunkach 2-5 przedstawiono bezwymiarowe wykresy ugięcia płyty oraz sił przekrojowych.

Widoczne jest, że w odległości $\eta>0$ bardzo szybko zanikają przemieszczenia i siły przekrojowe w półpaśmie płytowym na podłożu Winklera. Współczynnik Poissona praktycznie nie ma wpływu na wartości tych sił, natomiast znacznie wpływa na wartości ugięć.

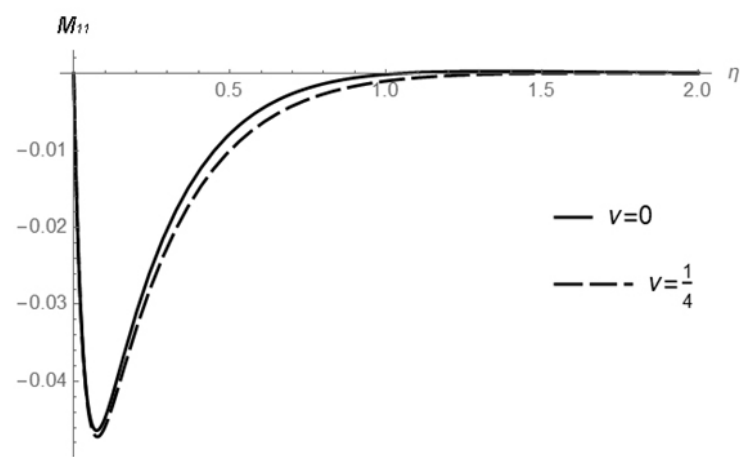

Rys. 3. Wykres momentów zginających $\frac{M_{11}}{a Q}$ w półpaśmie na podłożu Winklera dla $\xi=1 / 2$

Fig. 3. Graph of the bending moments $\frac{M_{11}}{a Q}$ in the plate on the Winkler subsoil for $\xi=1 / 2$

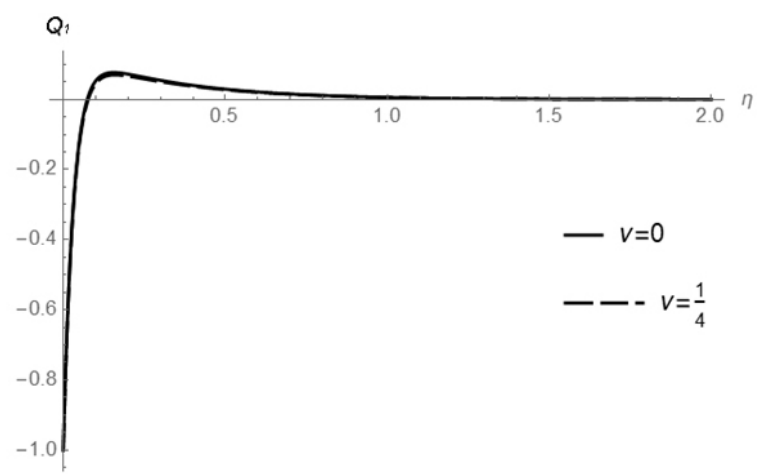

Rys. 5. Wykres siły poprzecznej $\frac{Q_{1}}{Q}$ w półpaśmie na podłożu Winklera dla $\xi=1 / 2$ Fig. 5. Graph of transverse force $\frac{Q_{1}}{Q}$ in the plate on the
Winkler subsoil for $\xi=1 / 2$ 


\section{ROZWIĄZANIE WEDŁUG TEORII PŁYT HENCKY'EGO-BOLLE'A PÓŁPASMA PŁYTOWEGO SPOCZYWAJACEGO NA PODŁOŻU SPRĘŻYSTYM WŁASOWA}

Dla półpasma płytowego przedstawionego na rysunku 1, spoczywającego na jednowarstwowym podłożu sprężystym Własowa, równanie różniczkowe (13) zapiszemy w postaci

$$
\nabla^{4} w\left(x_{\alpha}\right)-2 r_{3}^{2} \nabla^{2} w\left(x_{\alpha}\right)+s_{3}^{4} w\left(x_{\alpha}\right)=0
$$

gdzie $r_{3}{ }^{2}$ i $s_{3}{ }^{4}$ są dane wzorami (14), charakterystyki sprężyste $k$ i $t$, które wchodzą do wzorów (14), wyznacza się zgodnie ze wzorem (7).

Rozwiązanie jednorodnego układu równań (23) i (3) przewidujemy w postaci (16) oraz (17), w których współczynniki $\theta_{1}, \theta_{2}, \theta_{3}$ są dane wzorami (18), (19) i (20), z taką różnicą, że zamiast $r_{1}{ }^{2}$ i $s_{1}{ }^{4}$ należy wstawić wielkości $r_{3}{ }^{2}$ i $s_{3}{ }^{4}$ odpowiednio, które wyznaczymy ze wzoru (14). Momenty zginające, skręcające i siły poprzeczne wyznaczymy ze wzorów (21) i (22). W przypadku płyty spoczywającej na podłożu Własowa należy uwzględnić siłę poprzeczną w podłożu sprężystym, którą zapiszemy w układzie współrzędnych bezwymiarowych $\mathrm{w}$ postaci $S_{1}=\frac{2 t}{a} \frac{\partial w(\eta, \xi)}{\partial \eta}$.

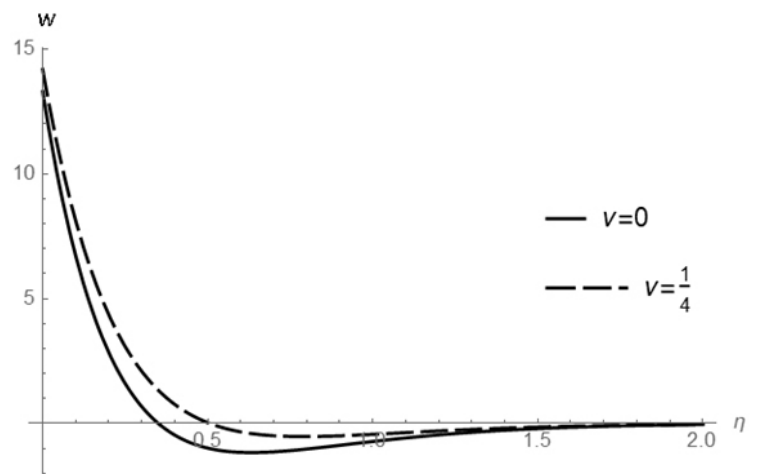

Rys. 6. Wykres ugięcia półpasma $\frac{w G_{p}}{Q}$ na podłożu Własowa dla $\xi=1 / 2$

Fig. 6. Graph of deflection $\frac{w G_{p}}{Q}$ of plate on the Vlasov's subsoil for $\xi=1 / 2$
Warunki brzegowe zapiszemy w postaci:

$M_{11}(0, \xi)=0, M_{12}(0, \xi)=-\hat{m}_{0}$,

$Q_{1}(0, \xi)+S_{1}(0, \xi)=-\hat{q}_{0}$.

Przyjmując liniową funkcję zanikania przemieszczeń $\vartheta(z)$ w postaci (9) oraz współczynniki $\delta, \delta_{1}, \delta_{2}, \delta_{3}$ (analogicznie jak w przypadku półpasma spoczywającego na podłożu Winklera), wyznaczymy ugięcie płyty, a z tym i siły przekrojowe w półpaśmie (rys. 6-9).

Analogicznie jak i w przypadku półpasma spoczywającego na podłożu sprężystym Winklera w odległości $\eta>0$ bardzo szybko zanikają przemieszczenia i siły przekrojowe w półpaśmie płytowym. Współczynnik Poissona praktycznie nie ma wpływu na wartości tych sił, natomiast znacznie wpływa na wartości ugięć.

Porównując ze sobą wyniki dla półpasma spoczywającego na podłożu Winklera oraz Własowa, na rysunkach 10-13 przedstawiono wykresy ugięć i momentów zginających w półpaśmie płytowym.

Przy obciążeniu „samorównoważnym” półpasma spoczywającego na podłożu sprężystym Własowa ugięcia są mniejsze niż $\mathrm{w}$ wariancie $\mathrm{z}$ podłożem Winklera zarówno w przypadku dla $v=0$, jak i $v=1 / 4$. Momenty zginające w półpaśmie są mniejsze w przypadku półpasma na podłożu Własowa. Wykresy dla momentów skręcających nie zostały przedstawione ze względu na to, że one są prawie identyczne.

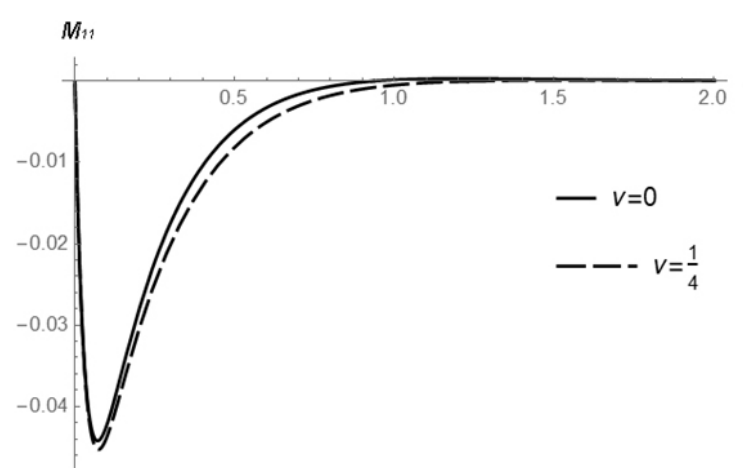

Rys. 7. Wykres momentów zginających $\frac{M_{11}}{a Q}$ w półpaśmie na podłożu Własowa dla $\xi=1 / 2$

Fig. 7. Graph of the bending moments $\frac{M_{11}}{a Q}$ in the plate on the Vlasov's subsoil for $\xi=1 / 2$ 


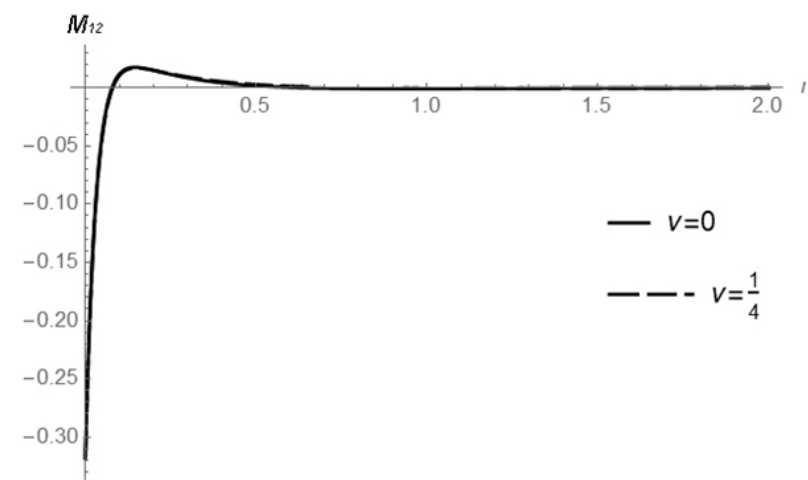

Rys. 8. Wykres momentów skręcających $\frac{M_{12}}{a Q}$ w półpaśmie na podłożu Własowa dla $\xi=0$

Fig. 8. Graph of the torsional moments $\frac{M_{12}}{a Q}$ in the plate on the Vlasov's subsoil for $\xi=0$

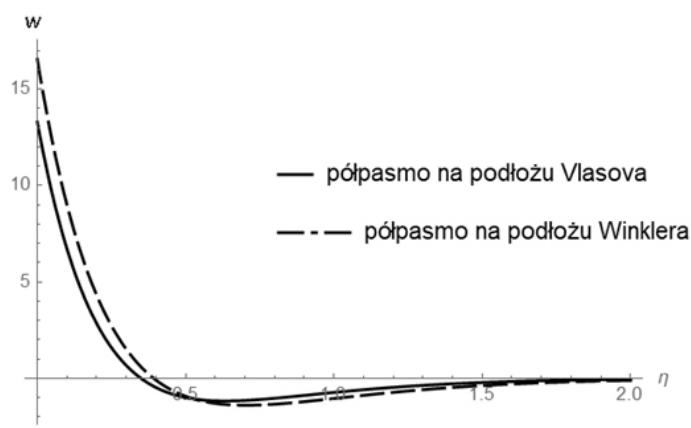

Rys. 10. Wykres ugięcia półpasma $\frac{w G_{p}}{Q}$ na podłożu Winklera oraz Własowa dla $v=0, \xi=1 / 2$

Fig. 10. Graph of deflection $\frac{w G_{p}}{Q}$ of plate on the Winkler and Vlasov's subsoil for $v=0, \xi=1 / 2$

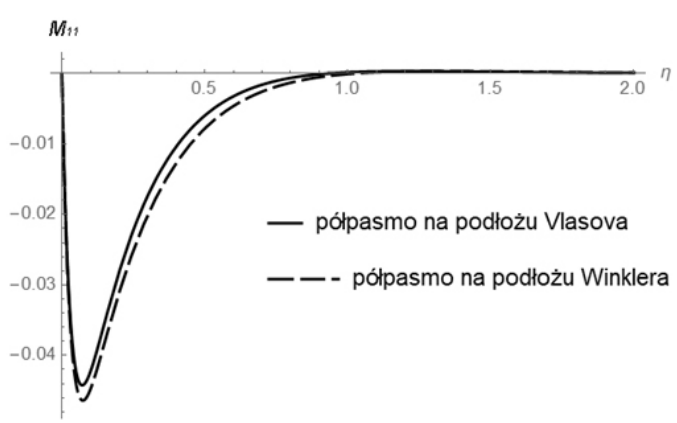

Rys. 12. Wykres momentów zginających $\frac{M_{11}}{a Q}$ w półpaśmie na podłożu Winklera oraz Własowa dla $v=0$,

Fig. 12. Graph of the bending moments $\frac{M_{11}}{a Q}$ of plate on the Winkler and Vlasov's subsoil for $v=0, \xi=1 / 2$

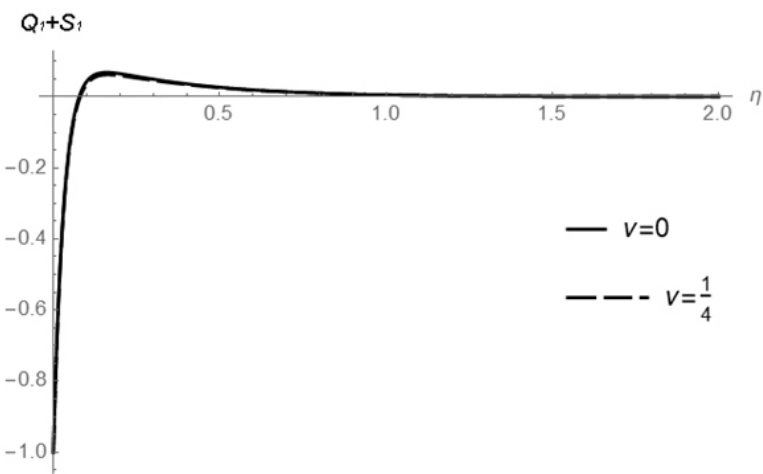

Rys. 9. Wykres uogólnionej siły poprzecznej $\frac{Q_{1}+S_{1}}{Q}$ w półpaśmie na podłożu Własowa dla $\xi=1 / 2$

Fig. 9. Graph of generalized lateral force $\frac{Q_{1}+S_{1}}{Q}$ in the plate on the Vlasov's subsoil for $\xi=1 / 2$

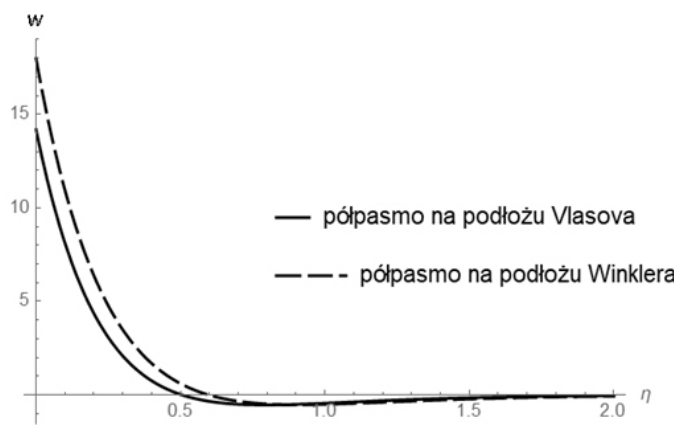

Rys. 11. Wykres ugięcia półpasma $\frac{w G_{p}}{Q}$ na podłożu Winklera oraz Własowa dla $v=1 / 4, \xi=1 / 2$

Fig. 11. Graph of deflection $\frac{w G_{p}}{Q}$ of plate on the Winkler and Vlasov's subsoil for $v=1 / 4, \xi=1 / 2$

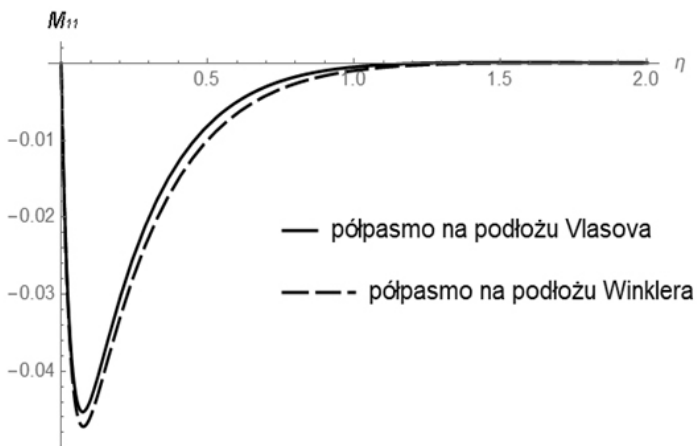

Rys. 13. Wykres momentów zginających $\frac{M_{11}}{a Q}$ w półpaśmie na podłożu Winklera oraz Własowa dla

$v=1 / 4, \xi=1 / 2$
Fig. 13. Graph of the bending moments $\frac{M_{11}}{a Q}$ of plate on the Winkler and Vlasov's subsoil for $v=1 / 4, \xi=1 / 2$ 


\section{PODSUMOWANIE}

W pracy rozpatrzono teorie płyt Kirchhoffa (cienkich) spoczywających na podłożu sprężystym Winklera, dwuparametrowym Własowa oraz uogólnioną teorię płyt Hencky'ego-Bolle'a (średniej grubości) spoczywających na wymienionych modelach podłoża gruntowego. Wyprowadzono równania różniczkowe dla płyt średniej grubości na podłożu sprężystym Winklera i Własowa. Na podstawie pracy Nagirniaka (2019) rozpatrzono przypadek cienkiego półpasma płytowego spoczywającego na podłożu sprężystym Winklera lub Własowa, obciążonego „samorównoważnie” na brzegu. Wykazano, że obciążenia tego typu nie wywołują przemieszczeń, a przy tym i sił przekrojowych w płycie cienkiej zarówno bez podłoża, jak i w wariancie z podłożem sprężystym. Niezerowe rozwiązanie otrzymujemy zaś w przypadku płyty średniej grubości spoczywającej na podłożu sprężystym. W płycie średniej grubości wpływ współczynnika Poissona na wartości ugięć jest znaczny, natomiast na wartości momentu zdecydowanie mniejszy. Widoczne jest też, że ekstremalne wartości momentu zginającego $M_{11}$ występują dla $\eta=0,07$. Ugięcie i momenty zginające półpasma płytowego obciążonego „samorównoważnie" na brzegu, spoczywającego na podłożu Własowa są mniejsze niż $\mathrm{w}$ wariancie $\mathrm{z}$ podłożem Winklera. Wykresy momentów skręcających w półpaśmie płytowym są bardzo zbliżone do siebie dla obu przypadków podłoża.

\section{PIŚMIENNICTWO}

Filonenko-Borodich, M. (1940). Nekotorye približennye teorii uprugogo osnovanija. Učënye zapiski $M G U, 46$, $3-18$.

Jemielita, G. (1992). Generalization of the Kerr foundation model. Journal of Theoretical and Applied Mechanics, 4 (30), 843-853.

Jemielita, G. (1994). Governing equations and boundary conditions of a generalized model of elastic foundation. Journal of Theoretical and Applied Mechanics, 4 (32), 887-901.

Jemielita, G. (2001). Teorie płyt sprężystych. W C. Woźniak (red.), Mechanika techniczna. Tom VIII. Mechanika sprężystych plyt i powłok. Warszawa: Wydawnictwo Naukowe PWN.

Jemielita, G. (2002). Coefficients of shear correction in transveresly nonhomogeneous moderately thick plates. Journal of Theoretical and Applied Mechanics, 1 (40), 73-84.

Jemioło, S. i Szwed, A. (2017). Zagadnienia statyki sprężystych pótprzestrzeni warstwowych. Wyd. II. Warszawa: Oficyna Wydawnicza PW.

Nagirniak, M. (2019). Ocena zasięgu efektu brzegowego w płytach Hencky'ego-Bolle'a o wybranych warunkach brzegowych. Acta Sci. Pol. Architectura, 18 (2), 93-105.

Pasternak, P. (1954). Osnovy novogo metoda rasčëta fundamentov na uprugom osnovanii pri pomošči dvuch kočficientov posteli. Moskwa: Gosudarstvennoe izdatelstvo literatury po stroitelstvu i architekturę.

Vlasov, V. i Leontiev, N. (1960). Balki, plity i oboločki na uprugom osnovanii. Moskwa: Gosudarstvennoe izdatelstvo fiziko-matemetičeskoj literatury.

\title{
HENCKY-BOLLE'S PLATES OF MEDIUM THICKNESS ON ELASTIC SUBSOIL
}

\begin{abstract}
The paper presents equations of theory of plates resting on elastic subsoil. Theories of thin and medium thickness plates applied to subsoils with one and two parameters, including Vlasov's and Winkler's subsoils, were analysed. The case of placing a "self-balancing" load on the edge of a half-band resting on the Vlasov's and Winkler's elastic subsoils was considered. It was proved that the so-called boundary effect occurs only in medium thickness plates and plates resting on Winkler's one-parameter and Vlasov's two-parameter elastic subsoils. The influence of the Poisson's ratio of the plate material on the deflection and cross-section forces in the plate half-band resting on subsoil was analysed. The solutions obtained using Hencky-Bolle's theory applied to plate half-band on Winkler's and Vlasov's subsoils were compared.
\end{abstract}

Key words: Kirchhoff's plates, Hencky-Bolle's plates, boundary effect, Vlasov's subsoil, Winkler's subsoil, "self-balancing" load 